\title{
Protective Effects of Coenzyme Q10 on Decreased Oxidative Stress Resistance Induced by Simvastatin
}

\author{
Aikkarach Kettawan ${ }^{1}$, Takayuki Takahashi ${ }^{1,2}$, Ratchanee Kongkachuichai ${ }^{3}$, \\ Somsri Charoenkiatkul ${ }^{3}$, Takeo Kishi ${ }^{1}$, and Tadashi Okamoto ${ }^{1,2, *}$ \\ ${ }^{1}$ Laboratory of Biochemistry, Division of Health Sciences and Social Pharmacy, Faculty of Pharmaceutical \\ Sciences, Kobe Gakuin University, Kobe 650-8586, Japan \\ ${ }^{2}$ Cooperative Research Center of Life Sciences, Kobe Gakuin University, Kobe 650-8586, Japan \\ ${ }^{3}$ Division of Food Chemistry, Institute of Nutrition, Mahidol University, Nakhon Pathom 73170, Thailand
}

Received 9 October, 2006; Accepted 25 October, 2006

\begin{abstract}
Summary The effects of simvastatin, an inhibitor of 3-hydroxy-3-methylglutaryl CoA reductase (HMG-CoA reductase), on oxidative stress resistance and the protective effects of coenzyme $Q(C o Q)$ were investigated. When simvastatin was administered orally to mice, the levels of oxidized and reduced $\mathrm{CoQ}_{9}$ and $\mathrm{CoQ}_{10}$ in serum, liver, and heart, decreased significantly when compared to those of control. The levels of thiobarbituric acid reactive substances induced by $\mathrm{Fe}^{2+}$-ascorbate in liver and heart mitochondria also increased significantly with simvastatin. Furthermore, cultured cardiac myocytes treated with simvastatin exhibited less resistance to oxidative stress, decreased time to the cessation of spontaneous beating in response to $\mathrm{H}_{2} \mathrm{O}_{2}$ addition, and decreased responsiveness to electrical field stimulation. These results suggested that oral administration of simvastatin suppresses the biosynthesis of $\mathrm{CoQ}$, which shares the same biosynthesis pathway as cholesterol up to farnesyl pyrophosphate, thus compromising the physiological function of reduced $\mathrm{CoQ}$, which possesses antioxidant activity. However, these undesirable effects induced by simvastatin were alleviated by coadministering $\mathrm{CoQ}_{10}$ with simvastatin to mice. Simvastatin also reduced the activity of NADPH-CoQ reductase, a biological enzyme that converts oxidized CoQ to the corresponding reduced $\mathrm{CoQ}$, while $\mathrm{CoQ}_{10}$ administration improved it. These findings may also support the efficacy of coadministering CoQ10 with statins.
\end{abstract}

Key Words: coenzyme $\mathbf{Q}_{10}$, ubiquinol-10, HMG-CoA reductase inhibitor, statin, oxidative stress

\section{Introduction}

Hypercholesterolemia is a well-known risk factor for coronary heart disease and arteriosclerosis. 3-hydroxy-3methylglutaryl-coenzyme A (HMG-CoA), the late-limiting enzyme in the biosynthesis of cholesterol through the

\footnotetext{
*To whom correspondence should be addressed.

Tel: +81-78-974-1551 Fax: +81-78-974-5689

E-mail: tadashi@pharm.kobegakuin.ac.jp
}

mevalonate pathway, converts HMG-CoA, a trimer of acetyl CoA molecules generated from fatty acid oxidation, to mevalonic acid, which is then further metabolized to eventually produce cholesterol [1]. Among various drugs developed to reduce serum cholesterol levels and subsequent risk for coronary events, HMG-CoA reductase inhibitors (statins), have proven to be extremely useful drugs [2-5].

While statins are very clinically effective drugs, adverse reactions such as rhabdomyolysis $[6,7]$ have been reported. Adverse reactions often affect tissues and cells with high energy metabolism, such as skeletal muscles, myocardium 
and smooth muscles, and to date, ultrastructural changes, including mitochondrial dysfunction $[8,9]$ and swelling, increased serum creatine kinase, induction of necrosis [10] or apoptosis [11-15], and abnormalities in calcium homeostasis [16] have been reported. However, the contributing factors and protective effects have not been elucidated.

Coenzyme Q (CoQ) is an essential carrier for the mitochondrial electron transport system and plays an important role in energy production. Exogenous $\mathrm{CoQ}_{10}$ has been shown to improve energy metabolism and activate energy production by cardiac myocytes. CoQ is distributed not only in mitochondria, but also in other subcellular fractions [17-19], and some CoQ always presents as reduced $\mathrm{CoQ}\left(\mathrm{H}_{2} \mathrm{CoQ}\right)$ [18]. $\mathrm{H}_{2} \mathrm{CoQ}$ is unstable when exposed to air, and can easily be oxidized into oxidized CoQ. In this manner, chemically unstable $\mathrm{H}_{2} \mathrm{CoQ}$ is thought to exist in the body to serve as an antioxidant. We have reported previously [20-22] that a novel cytosolic NADPH-CoQ reductase is responsible for the reduction of $\mathrm{CoQ}_{10}$ to $\mathrm{H}_{2} \mathrm{CoQ}_{10}$ in biomembranes. Furthermore, we observed that prolonged supplementation with $\mathrm{CoQ}_{10}$ caused a significant increase in the NADPH-CoQ reductase activity, and protected partially hepatotoxicity induced by carbon tetrachloride and $\mathrm{H}_{2} \mathrm{O}_{2}$. In addition, enhanced levels of $\mathrm{H}_{2} \mathrm{CoQ}_{10}$ and NADPH-CoQ reductase activity showed more resistant to oxidative stress than those of normal levels. These results suggested that $\mathrm{H}_{2} \mathrm{CoQ}{ }_{10}$ with NADPH-CoQ reductase constituted a fundamental defense system against oxidative stress in cellular membrane. According to some reports, another reductases such as $\mathrm{NAD}(\mathrm{P}) \mathrm{H}$ :quinone oxidoreductase 1 (NQO1, DT-diaphorase) $[23,24]$, thiredoxin reductase [25] and lipoamide dehydrogenase $1[26,27]$ may also involve in the reduction of CoQ to $\mathrm{H}_{2} \mathrm{CoQ}$. The in vitro experiments using low-density lipoprotein (LDL) [28, 29], biological membranes [30] or lecithin liposome membranes [31,32] have clarified that $\mathrm{H}_{2} \mathrm{CoQ}$ possesses potent antioxidant activity. To date, two mechanisms for the antioxidant activities of $\mathrm{H}_{2} \mathrm{CoQ}$ have been clarified. In one mechanism, $\mathrm{H}_{2} \mathrm{CoQ}$ directly eliminates lipid peroxyl radicals $[31,32]$, and in the other, $\mathrm{H}_{2} \mathrm{CoQ}$ indirectly acts as an antioxidant by regenerating $\alpha$-tocopherol from $\alpha$-tocopheroxyl radicals formed by a reaction between $\alpha$-tocopherol and lipid peroxyl radicals ( $\alpha$-tocopherolsaving action). It has been clarified that $\mathrm{H}_{2} \mathrm{CoQ}$ exhibits potent antioxidant activity through these two mechanisms.

CoQ is supplied exogenously through diet [33] or endogenously through biosynthesis [34, 35]. Therefore, supply reduction in either exogenous or endogenous CoQ may affect its physiological functions. Because cholesterol and CoQ share the same biosynthesis pathway until farnesyl pyrophosphate [34, 35], inhibition of HMG-CoA reductase, which is the rate-limiting enzyme in cholesterol biosynthesis, is likely to affect the metabolism and physiological functions of $\mathrm{CoQ}$, including $\mathrm{H}_{2} \mathrm{CoQ}$ [35]. In fact, many investigators have pointed out that statin administration lowers CoQ in serum (plasma) [9, 36-38] and tissue [36], and that statins hinder normal function of the heart [39] and skeletal muscles [40].

In this study, in order to administer $\mathrm{HMG}-\mathrm{CoA}$ reductase inhibitors safely and efficiently, we elucidated the change of oxidative stress resistance induced by simvastatin and its protective effects of $\mathrm{CoQ}_{10}$ were investigated.

\section{Materials and Methods}

\section{Reagents}

All reagents were commercially available and were of reagent grade. The solvent for high performance liquid chromatography (HPLC) was purchased from Wako Pure Chemical Industries, Ltd., Osaka. Commercially available reagent grade methanol for HPLC was used after distillation. Authentic $\mathrm{CoQ}_{9}$ and $\mathrm{CoQ}_{10}$ for HPLC were donated by Nisshin Pharma Inc., Tokyo. As simvastatin, $5 \mathrm{mg}$ Lipovas tablets (pharmaceutical drug, Banyu Pharmaceutical Co. Ltd., Tokyo), and as CoQ10, $30 \mathrm{mg}$ LivLon Soft Capsules (dietary and health food, Nisshin Pharma Inc., Tokyo) were used in the experiment for oral administration to mice. Each compound was dissolved in drinking water and homogenized by ultrasonic treatment.

\section{Animals}

Ten week-old male specific pathogen-free (SPF) ICR mice were used. To prepare cultured cardiac myocytes, female SPF ICR mice on the fourth day of gestation were used. All mice were purchased from SLC Japan (Shizuoka). Simvastatin and $\mathrm{CoQ}_{10}$ were administered orally, and by measuring daily water intake for each mouse for three days before the study, drug solutions were prepared such that each mouse would consume the predetermined dosages. Simvastatin and CoQ 10 were mixed in drinking water just prior to administration, and drinking water was prepared daily. Based on body weight, the mice were divided into four groups of five mice each [(1) control group (no simvastatin or CoQ 10 ), (2) simvastatin group (1 mg/day of simvastatin), (3) CoQ 10 group ( $3 \mathrm{mg} /$ day of $\mathrm{CoQ}_{10}$ ), and (4) simvastatin $+\mathrm{CoQ}_{10}$ group ( $1 \mathrm{mg} /$ day of simvastatin $+3 \mathrm{mg} /$ day of $\left.\left.\mathrm{CoQ}_{10}\right)\right]$, and the dosage of simvastatin and $\mathrm{CoQ}_{10}$ was set as follows: each mouse was weighed daily, and simvastatin and $\mathrm{CoQ}_{10}$ were administered for two consecutive weeks. Simvastatin and $\mathrm{CoQ}_{10}$ were administered orally to pregnant mice from the fourth to fifteenth day of gestation (fetal ventricular myocardium was excised from pregnant mice on the fifteenth day of gestation). Mice were fed Lab MR Stock (standard feed, SLC Japan). All animal experiments were conducted in accordance with the manual compiled by the Kobe University Animal Ethics Committee. 


\section{Cultured cardiac myocyte preparation and observation}

The fetal ventricular myocardium was excised from pregnant mice prepared as described above from the fourth to fifteenth day of gestation, and cultured cardiac myocytes were prepared according to the method of Goshima et al. [41]. Cardiac myocytes were cultured using Eagle MEM containing $10 \%$ fetal bovine serum under $5 \% \mathrm{CO}_{2}$ in air at $37^{\circ} \mathrm{C}$ for 2 days. To avoid antioxidant contamination, including $\mathrm{CoQ}_{10}$, originating from fetal bovine serum, cells were washed using $10 \mathrm{ml}$ of Dulbecco's phosphate-buffered saline twice $1 \mathrm{~h}$ before the study, and after replacing culture solution with Eagle MEM free of fetal bovine serum, cells were incubated under $5 \% \mathrm{CO}_{2}$ in air at $37^{\circ} \mathrm{C}$ for at least one hour. A 1- to 2-mm-diameter cardiac myocyte sheet containing at least $10^{4}$ cells was produced after cultivation for 2 days. The spontaneous beating of cultured cardiac myocyte sheet was measured in an incubator at $36 \pm 1^{\circ} \mathrm{C}$ and under $5 \% \mathrm{CO}_{2}$ in air using a phase contrast microscope. Electrical field stimulation was performed by the method of Nakamura et al., as follows [42]: two platinum electrodes, $1 \mathrm{~Hz}$, pulse length of $50 \mathrm{~ms}$, and pulse amplitude of $100 \mathrm{~V}$.

Preparation of mitochondria and cytosolic fraction from mice liver and heart

Intracellular fractions of mice heart and liver were prepared by differential centrifugation as described previously [18]. The purity of the cytosol and mitochondrial fractions was determined by measuring their marker enzyme activities.

\section{Measurement of total serum cholesterol level}

Total serum cholesterol was measured spectrophotometrically by the enzyme method [43].

Measurement of CoQ levels in serum, cytosolic fraction and tissue

Reduced and total CoQ (sum of oxidized and reduced CoQ) levels were measured by HPLC-electrochemical detector in accordance with the method of Okamoto et al. [44]. CoQ in the cytosolic fraction was expressed as pmol per mg protein.

Measurement of lipid peroxidation induced by $\mathrm{Fe}^{2+}$-ascorbate Lipid peroxidation was carried out using $50 \mathrm{mM}$ ascorbic acid and $5 \mathrm{mM} \mathrm{FeSO}_{4}$ according to the method of Takei et al. [45]. Thiobarbituric acid reactive substances (TBARS) were extracted using $3 \mathrm{ml}$ of $\mathrm{n}$-butanol and were measured by the fluorometrical method (Ex: $515 \mathrm{~nm}, \mathrm{Em}$ : $553 \mathrm{~nm}$ ). The standard was 1,1,3,3-tetraethoxypropane in the TBARS assay.

Measurement of NADPH-CoQ reductase activity in cytoplasm

NADPH-CoQ activity in cytoplasm of liver and heart was measured according to the method of Takahashi et al. [46].
This activity was expressed as the amount of CoQ ${ }_{10}$ (pmol) reduced per minute per $\mathrm{mg}$ protein.

\section{Protein content and data analysis}

Protein content was determined as described by Lowry et al. [47]. The Student's unpaired $t$ test were used for statistical analysis and statistical significance was assigned for any $p$ values less than 0.05 .

\section{Results}

Changes in reduced and total CoQ levels in mouse serum, heart, liver, and their cytosolic and mitochondorial fractions induced by simvastatin administration (Table 1)

When $1 \mathrm{mg} / \mathrm{kg}$ body weight simvastatin was orally administered to mice everyday for two weeks, total serum cholesterol decreased significantly when compared to controls (no simvastatin or $\mathrm{CoQ}_{10}$ ). Furthermore, coadministration of simvastatin and $\mathrm{CoQ}_{10}$ lowered serum cholesterol in a similar manner. This result shows that $\mathrm{CoQ}_{10}$ itself does not affect the cholesterol lowering activity of simvastatin.

Simvastatin administration significantly lowered the levels of both serum $\mathrm{CoQ}_{9}$, the predominant homologue in mice, and $\mathrm{CoQ}_{10}$, as compared to those of control. Furthermore, simvastatin also singnificantly lowered reduced, oxidized and total $\mathrm{CoQ}_{10}$ levels, and did not affect the ratio of reduced CoQ to total CoQ.

When $3 \mathrm{mg} / \mathrm{kg}$ body weight CoQ 10 was orally administered to mice everyday for two weeks, irrespective of whether CoQ 10 was administered alone or with simvastatin, serum levels increased by about 6-fold. These results show that simvastatin administration does not affect the serum $\mathrm{CoQ}_{10}$ increasing level by $\mathrm{CoQ}_{10}$ administration. CoQ 10 itself did not affect the levels of serum $\mathrm{CoQ}_{9}$, the main homologue in mice.

Like the levels of $\mathrm{CoQ}_{9}$ and $\mathrm{CoQ}_{10}$ in serum, the levels of $\mathrm{CoQ}_{9}$ and $\mathrm{CoQ}_{10}$ in the liver and heart were significantly lowered by simvastatin administration. Furthermore, this lowering action was observed in mitochondrial and cytosolic fractions of liver and heart.

Oxidative stress resistance-decreasing effects of simvastatin

Changes in oxidative stress resistance due to simvastatin administration were evaluated using heart and liver mitochondria and cultured cardiac myocytes.

The TBARS levels produced using $\mathrm{Fe}^{2+}$-ascorbate in heart mitochondria at $15 \mathrm{~min}$ after the start of the reaction for the simvastatin group was significantly higher when compared to the other groups (Table 2). At two hours after the start of the reaction, the TBARS level $(\mathrm{mM})$ in the control, simvastatin, $\mathrm{CoQ}_{10}$ and simvastatin $+\mathrm{CoQ}_{10}$ groups was $0.67,0.81,0.63$ and 0.66 , respectively, and $\mathrm{CoQ}_{10}$ clearly lowered significantly the TBARS level as compared to that 
Table 1. Effect of simvastatin on serum cholesterol and Coenzyme Q contents in Serum, Heart and Liver

\begin{tabular}{|c|c|c|c|c|}
\hline & \multicolumn{4}{|c|}{ Administration } \\
\hline & Control & Sim & $\mathrm{CoQ}_{10}$ & $\mathrm{Sim}+\mathrm{CoQ}_{10}$ \\
\hline \multicolumn{5}{|l|}{ Serum } \\
\hline Cholesterol (mg/dl) & $131 \pm 25$ & $94 \pm 31^{*}$ & $141 \pm 15$ & $90 \pm 22 *$ \\
\hline Total CoQ ${ }_{9}(\mathrm{ng} / \mathrm{ml})^{1}$ & $71.9 \pm 3.1$ & $60.2 \pm 8.9^{*}$ & $75.8 \pm 3.4$ & $66.1 \pm 6.4^{*}$ \\
\hline Reduced $\mathrm{CoQ}_{9}(\mathrm{ng} / \mathrm{ml})$ & $58.0 \pm 2.2$ & $48.0 \pm 8.8^{*}$ & $62.9 \pm 3.7$ & $54.3 \pm 6.8$ \\
\hline Reduced/Total $(\%)^{2}$ & $80.4 \pm 3.0$ & $79.3 \pm 3.9$ & $83.0 \pm 1.9$ & $81.2 \pm 5.5$ \\
\hline Total CoQ ${ }_{10}(\mathrm{ng} / \mathrm{ml})^{1}$ & $24.4 \pm 1.3$ & $19.3 \pm 1.5^{* *}$ & $155.3 \pm 48.2 * *$ & $143.7 \pm 56.8 * *$ \\
\hline Reduced CoQ ${ }_{10}(\mathrm{ng} / \mathrm{ml})$ & $19.2 \pm 1.7$ & $15.4 \pm 1.5^{* *}$ & $128.7 \pm 37.3^{* *}$ & $115.6 \pm 54.2 * *$ \\
\hline Reduced/Total $(\%)^{2}$ & $78.5 \pm 2.6$ & $80.1 \pm 4.9$ & $83.3 \pm 2.9^{*}$ & $78.0 \pm 6.1$ \\
\hline \multicolumn{5}{|l|}{ Liver } \\
\hline Total CoQ ${ }_{9}(\mu \mathrm{g} / \mathrm{g})^{1}$ & $39.3 \pm 5.0$ & $30.5 \pm 3.1^{*}$ & $44.6 \pm 2.8^{*}$ & $37.4 \pm 5.6$ \\
\hline Reduced CoQ ${ }_{9}(\mu \mathrm{g} / \mathrm{g})$ & $24.7 \pm 4.9$ & $18.4 \pm 2.6^{*}$ & $29.8 \pm 2.6^{*}$ & $23.5 \pm 5.7$ \\
\hline Reduced/Total $(\%)^{2}$ & $62.6 \pm 6.0$ & $60.2 \pm 4.9$ & $66.8 \pm 3.7^{*}$ & $63.2 \pm 6.7$ \\
\hline Total CoQ $10(\mu \mathrm{g} / \mathrm{g})^{1}$ & $3.3 \pm 0.6$ & $2.5 \pm 0.3^{*}$ & $9.1 \pm 1.8^{* *}$ & $8.8 \pm 2.3^{* *}$ \\
\hline Reduced CoQ10 $(\mu \mathrm{g} / \mathrm{g})$ & $2.0 \pm 0.4$ & $1.4 \pm 0.3^{*}$ & $6.1 \pm 1.4^{* *}$ & $5.6 \pm 1.5^{* *}$ \\
\hline Reduced/Total $(\%)^{2}$ & $59.8 \pm 4.1$ & $57.3 \pm 4.2$ & $66.0 \pm 4.9^{*}$ & $64.0 \pm 4.1^{*}$ \\
\hline \multicolumn{5}{|l|}{ Mitochondria } \\
\hline Total $\mathrm{CoQ}_{10}{ }^{1}$ ( $\mathrm{pmol} / \mathrm{mg}$ protein) & $13.7 \pm 1.3$ & $10.0 \pm 1.5^{* *}$ & $21.8 \pm 2.2^{* *}$ & $17.0 \pm 1.1^{*}$ \\
\hline \multicolumn{5}{|l|}{ Cytosol } \\
\hline Total $\mathrm{CoQ}_{10}{ }^{1}(\mathrm{pmol} / \mathrm{mg}$ protein) & $2.5 \pm 0.2$ & $2.4 \pm 0.1^{*}$ & $3.3 \pm 0.2 * *$ & $3.0 \pm 0.2 * *$ \\
\hline \multicolumn{5}{|l|}{ Heart } \\
\hline Total $\mathrm{CoQ}_{9}(\mu \mathrm{g} / \mathrm{g})^{1}$ & $214.5 \pm 36.0$ & $171.8 \pm 22.4^{*}$ & $225.4 \pm 30.9$ & $186.1 \pm 6.3^{*}$ \\
\hline Reduced CoQ 9 ( $\mu \mathrm{g} / \mathrm{g})$ & $91.5 \pm 8.7$ & $71.0 \pm 10.1^{*}$ & $98.8 \pm 9.5$ & $81.9 \pm 8.9^{*}$ \\
\hline Reduced/Total $(\%)^{2}$ & $43.4 \pm 5.8$ & $41.4 \pm 2.8$ & $44.4 \pm 6.4$ & $45.0 \pm 4.0$ \\
\hline Total CoQ ${ }_{10}(\mu \mathrm{g} / \mathrm{g})^{1}$ & $24.8 \pm 5.2$ & $21.0 \pm 3.2 *$ & $26.2 \pm 3.1$ & $23.1 \pm 3.4$ \\
\hline Reduced CoQ $10(\mu \mathrm{g} / \mathrm{g})$ & $8.5 \pm 1.2$ & $7.0 \pm 1.2 *$ & $9.9 \pm 1.2$ & $8.0 \pm 1.4$ \\
\hline Reduced/Total $(\%)^{2}$ & $35.0 \pm 6.8$ & $33.8 \pm 3.3$ & $38.2 \pm 4.8$ & $35.2 \pm 6.5$ \\
\hline \multicolumn{5}{|l|}{ Mitochondria } \\
\hline Total CoQ ${ }_{10}^{1}(\mathrm{pmol} / \mathrm{mg}$ protein) & $284.8 \pm 18.7$ & $247.8 \pm 17.7^{*}$ & $313.9 \pm 11.4^{*}$ & $270.9 \pm 20.8$ \\
\hline \multicolumn{5}{|l|}{ Cytosol } \\
\hline Total CoQ ${ }_{10}^{1}(\mathrm{pmol} / \mathrm{mg}$ protein) & $17.4 \pm 0.8$ & $13.4 \pm 1.1^{*}$ & $16.8 \pm 1.5$ & $15.9 \pm 1.0$ \\
\hline
\end{tabular}

Control: untreated group, Sim: simvastatin-treated group, CoQ $10:$ CoQ 10 -treated group, Sim $+\mathrm{CoQ}_{10}:$ simvastatin and CoQ 10 -cotreated group. The values given are means $\pm \mathrm{SD}(n=5) .{ }^{1}$ Total $\mathrm{CoQ}_{\mathrm{n}}$ is the sum of both reduced and oxidized form of $\mathrm{CoQ}_{\text {n. }}{ }^{2}$ Reduced $\mathrm{CoQ}_{10} /$ Total $\mathrm{CoQ}_{10} \times 100 .{ }^{*} p<0.05,{ }^{*} p<0.005$ vs control (untreated) group.

of simvastatin group.

Like heart mitochondria, simvastatin administration increased the amount of TBARS with time in liver mitochondria. However, unlike heart mitochondria, suppression of TBARS by CoQ10 was not seen for the first hour of the reaction, and significant suppression was confirmed only after two hours (Table 3).

Changes in oxidative stress $\left(\mathrm{H}_{2} \mathrm{O}_{2}\right)$ resistance [42] were determined using cultured cardiac myocyte sheets prepared from fetal ventricular myocardium obtained from pregnant mice on oral simvastatin administration in terms of spontaneous beating and electrical field stimulation response (Fig. 1). Prior to the experiment, cultured cardiac myocytes were incubated with $10 \mu \mathrm{M} \mathrm{CoQ}{ }_{10}\left(\mathrm{CoQ}_{10}\right.$-treated group) for 6 hours, $3 \mu \mathrm{M}$ simvastatin (simvastatin-treated group) for 2 hours, or $10 \mu \mathrm{M} \mathrm{CoQ} 10$ for 6 hours and $3 \mu \mathrm{M}$ simvastatin for 2 hours (simvastatin and CoQ 10 -cotreated group). Under microscopic observations, in this point, any morphological changes of cells were not observed.

When $50 \mu \mathrm{M} \mathrm{H}_{2} \mathrm{O}_{2}$, an active oxygen species, was added to untreated cultured cardiac myocytes, beating stopped after $17 \mathrm{~min}$. Furthermore, immediately after cessation, electric field stimulation was applied to the cells. When the time for the cells to respond to the stimulation was measured, electrical field-stimulated beating continued for $28 \mathrm{~min}$. With cardiac myocytes treated by simvastatin, the 
Table 2. Protective effect of Coenzyme $\mathrm{Q}_{10}$ on lipid peroxidation of heart mitochondria induced by $\mathrm{Fe}^{2+}$-ascorbate

\begin{tabular}{lllll}
\hline \multirow{2}{*}{ Group } & \multicolumn{4}{c}{ TBARS $(\mathrm{mM})$} \\
\cline { 2 - 5 } & \multicolumn{1}{c}{$15 \mathrm{~min}$} & \multicolumn{1}{c}{$30 \mathrm{~min}$} & $1 \mathrm{~h}$ & $2 \mathrm{~h}$ \\
\hline Control & $0.46 \pm 0.04^{\mathrm{e})}$ & $0.67 \pm 0.03$ & $0.61 \pm 0.02^{\mathrm{d})}$ & $0.67 \pm 0.01^{\mathrm{f})}$ \\
Sim & $0.60 \pm 0.05^{\mathrm{b})}$ & $0.72 \pm 0.03$ & $0.71 \pm 0.07^{\mathrm{a}}$ & $0.81 \pm 0.02^{\mathrm{c})}$ \\
CoQ $_{10}$ & $0.46 \pm 0.01^{\mathrm{e}}$ & $0.57 \pm 0.02^{\mathrm{b}), \mathrm{f})}$ & $0.57 \pm 0.03^{\mathrm{d})}$ & $0.63 \pm 0.04^{\mathrm{f}}$ \\
$\operatorname{Sim}+\mathrm{CoQ}_{10}$ & $0.41 \pm 0.01^{\mathrm{f}}$ & $0.61 \pm 0.06^{\mathrm{d})}$ & $0.60 \pm 0.02^{\mathrm{d})}$ & $0.66 \pm 0.02^{\mathrm{f}}$ \\
\hline
\end{tabular}

Control: untreated group, Sim: simvastatin-treated group, CoQ 10 : CoQ 10 -treated group, $\mathrm{Sim}+\mathrm{CoQ}_{10}$ : simvastatin and $\mathrm{CoQ}_{10}$-cotreated group. The values given are means $\pm \mathrm{SD}(n=5)$. ${ }^{\mathrm{a})} p<0.05,{ }^{\mathrm{b}} p<0.01$, and ${ }^{c} p<0.001$ vs control (untreated) group at each indicated time. ${ }^{\mathrm{d})} p<0.05$, ${ }^{\mathrm{e}} p<0.01$, and ${ }^{\text {f) }} p<0.001$ vs simvastatin-treated group at each indicated time.

Table 3. Protective effect of Coenzyme $\mathrm{Q}_{10}$ on lipid peroxidation of liver mitochondria induced by $\mathrm{Fe}^{2+}$-ascorbate

\begin{tabular}{lllll}
\hline \multirow{2}{*}{ Group } & \multicolumn{4}{c}{ TBARS $(\mathrm{mM})$} \\
\cline { 2 - 5 } & \multicolumn{1}{c}{$15 \mathrm{~min}$} & \multicolumn{1}{c}{$30 \mathrm{~min}$} & \multicolumn{1}{c}{$1 \mathrm{~h}$} & \multicolumn{1}{c}{$\mathrm{h}$} \\
\hline Control & $0.69 \pm 0.02$ & $0.86 \pm 0.08$ & $0.80 \pm 0.04^{\mathrm{d})}$ & $0.85 \pm 0.05^{\text {c) }}$ \\
Sim & $0.71 \pm 0.03$ & $0.89 \pm 0.03$ & $0.94 \pm 0.06^{\text {b) }}$ & $0.94 \pm 0.02^{\text {a) }}$ \\
CoQ10 & $0.65 \pm 0.03^{\text {c) }}$ & $0.74 \pm 0.05^{\text {a), d }}$ & $0.63 \pm 0.08^{\text {b), e) }}$ & $0.66 \pm 0.08^{\text {b), e) }}$ \\
Sim + CoQ $_{10}$ & $0.72 \pm 0.03$ & $0.88 \pm 0.03$ & $0.89 \pm 0.06^{\text {a) }}$ & $0.86 \pm 0.05^{\text {c) }}$ \\
\hline
\end{tabular}

Control: untreated group, Sim: simvastatin-treated group, CoQ 10 : CoQ 10 -treated group, $\mathrm{Sim}+\mathrm{CoQ}_{10}$ : simvastatin and $\mathrm{CoQ}_{10}$-cotreated group. The values given are means $\pm \mathrm{SD}(n=5)$. ${ }^{\mathrm{a})} p<0.05$ and ${ }^{\text {b) }} p<0.01$ vs control (untreated) group at each indicated time. ${ }^{\text {c) }} p<0.05$, d) $p<0.01$, and e) $p<0.001$ vs simvastatin-treated group at each indicated time.
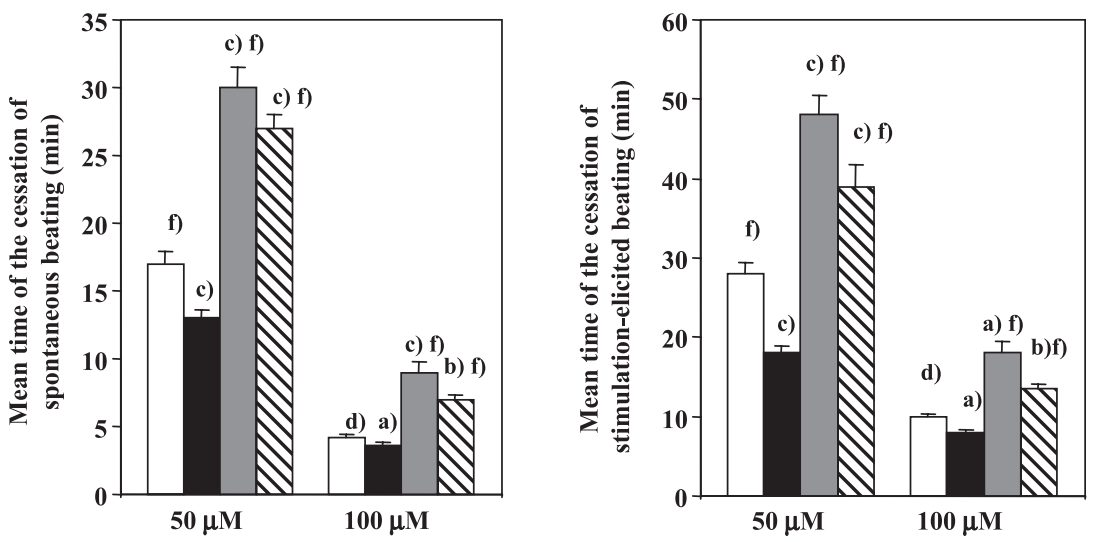

Concentration of $\mathrm{H}_{2} \mathrm{O}_{2}$

Control $\quad \operatorname{Sim} \quad \square \quad \operatorname{CoQ}_{10} \quad \mathrm{~W} \operatorname{Sim}+\mathrm{CoQ}_{10}$

Fig. 1. Protective effect of Coenzyme $\mathrm{Q}_{10}$ on beating impairment of cultured cardiac myocytes induced by simvastatin. The value given are means $\pm \mathrm{SD}(n=5)$. ${ }^{\mathrm{a})} p<0.05,{ }^{\mathrm{b})} p<0.01$, and ${ }^{\mathrm{c})} p<0.001$ vs control (untreated) group. ${ }^{\mathrm{d})} p<0.05$, ${ }^{\mathrm{e})} p<0.01$, and ${ }^{\text {f) }} p<0.001$ vs simvastatin-treated group. 
length of time to cessation was $13 \mathrm{~min}$, and the electric field stimulation response time was $18 \mathrm{~min}$, thus suggesting that simvastatin lowers oxidative stress resistance. On the other hand, $\mathrm{CoQ}_{10}$ increased the oxidative stress resistance of cardiac myocytes, and when compared to those of simvastatin group, spontaneous beating and electric field stimulation response time were significantly longer. The results were the same when $100 \mu \mathrm{M} \mathrm{H}_{2} \mathrm{O}_{2}$ was added to cardiac myocytes, but the effects of $\mathrm{CoQ}_{10}$ on spontaneous beating and electric field stimulation response time were not as great as when $50 \mu \mathrm{M} \mathrm{H}_{2} \mathrm{O}_{2}$ was added.

NADPH-CoQ reductase activity-lowering effect of simvastatin (Fig 2)

NADPH-CoQ reductase is one of the CoQ reductases in the cytoplasm, and we have reported previously that NADPH-CoQ reductase activity changes due to various oxidative stresses [48].

As shown in Fig. 2, when compared to the control group, cytoplasmic NADPH-CoQ reductase activity in the liver and heart in the simvastatin group were significantly lower when compared to those of control. CoQ 10 administration increased NADPH-CoQ reductase activity in the liver and heart, and the NADPH-CoQ reductase activity in the simvastatin and $\mathrm{CoQ}_{10}$-cotreated group was higher than that of the simvastatin group.
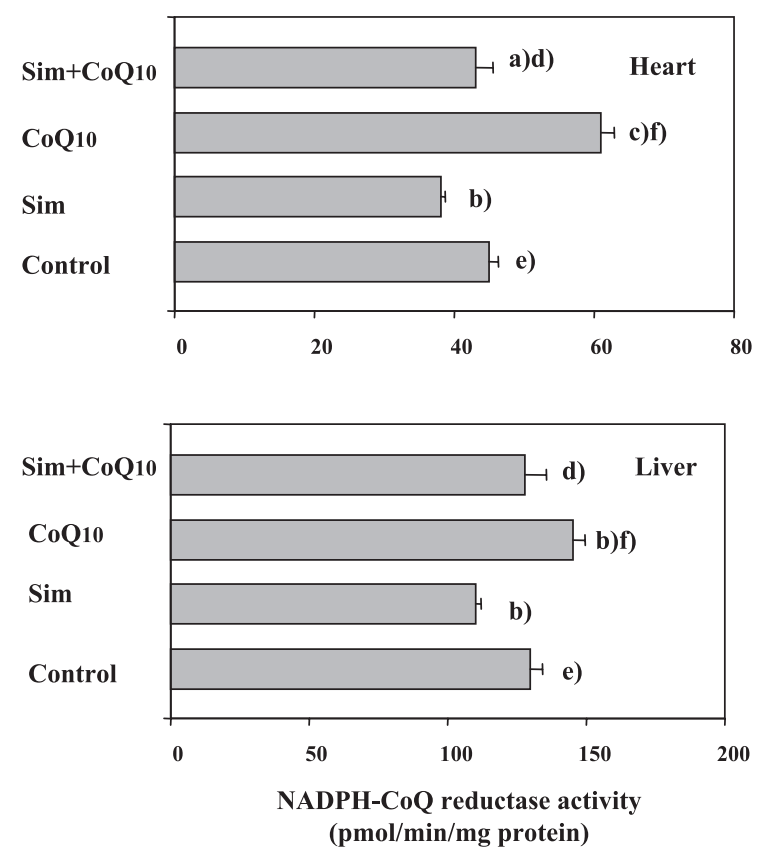

Fig. 2. Effect of simvastatin on cytosolic NADPH-CoQ reductase activities in heart and liver. The value given are means $\pm \mathrm{SD}(n=5) .{ }^{\mathrm{a})} p<0.05,{ }^{\mathrm{b}} p<0.01$, and ${ }^{\mathrm{c}} p<0.001$ vs control (untreated) group. ${ }^{\mathrm{d})} p<0.05,{ }^{\mathrm{e})} p<0.01$, and ${ }^{\text {f) }} p<0.001$ vs simvastatin-treated group.

\section{Discussion}

The nutritional sufficiency of CoQ is affected by both endogenous and exogenous $\mathrm{CoQ}$, and a reduction in one source is thought to markedly affect its physiological function. We reported previously [49] that serum $\mathrm{CoQ}_{10}$ levels in patients on total parenteral nutrition (TPN) decreased significantly after TPN and never reached zero following TPN. These results suggest that the decrease in serum $\mathrm{CoQ}_{10}$ levels after TPN is dependent on dietary (exogenous) CoQ 10 and that the residual serum CoQ 10 levels following TPN are dependent on biosynthesized (endogenous) $\mathrm{CoQ}_{10}$. However, the physiological changes induced by insufficient supply of endogenous $\mathrm{CoQ}_{10}$ have been unknown.

The CoQ biosynthesis pathway for eukaryotic cells has already been clarified $[34,35]$. CoQ shares the same biosynthetic pathway as cholesterol up to farnesyl pyrophosphate, and statins, which inhibit the rate-limiting enzyme of cholesterol biosynthesis, block the upstream section of the CoQ biosynthesis pathway. Therefore, statins affect CoQ biosynthesis greatly. Furthermore, the CoQ level in the body has been reported to decrease after the age of 20 years, and this decrease is marked in tissues with high energy metabolism, such as the heart [50]. Decreased CoQ 10 might be thus a serious problem, as most hypercholesterolemia patients who take statins are elderly.

Decrease in $\operatorname{CoQ}$ levels induced by oral administration of HMG-CoA reductase inhibitor

As shown in Table 1, oral administration of simvastatin significantly decreased not only serum cholesterol levels, but also serum and tissue $\mathrm{CoQ}_{9}$ and $\mathrm{CoQ}_{10}$ levels. Simvastatin also decreased both reduced and oxidized forms of $\mathrm{CoQ}_{9}$ and CoQ10. Many investigators have pointed out that statins lower serum and tissue CoQ levels $[9,36-38]$, but the effects of decreased $\mathrm{CoQ}$ on the body have not been fully elucidated. Folkers et al. reported that patients on statin therapy exhibited cardiac dysfunction [39]. The most important physiological action of $\mathrm{CoQ}_{10}$ is to improve energy metabolism by serving as an essential factor in the mitochondrial electron transfer system, and this action is accepted as the physiological action of $\mathrm{CoQ}_{10}$. Therefore, reduced CoQ levels may affect skeletal muscles and myocardium with active energy metabolism. In fact, muscle pain or weakness with high creatine kinase levels is the major adverse effects of statins [2]. In the present study, the levels of $\mathrm{CoQ}$, in cytoplasm where NADPH-CoQ reductase are present, as well as in the mitochondria were measured (Table 1), and the results confirmed that statin administration reduces CoQ levels in mitochondria and cytoplasm among intracellular organelles. 
Decreased oxidative stress resistance due to oral administration of HMG-CoA reductase inhibitor

In addition to energy production activation, another important physiological action of $\mathrm{CoQ}_{10}$ is as an antioxidant in vivo. Therefore, when simvastatin administration lowers CoQ levels in the body, endogenous antioxidative function may be affected to some degree. In general, orally taken oxidized $\mathrm{CoQ}_{10}$ is absorbed by epithelial cells in the small intestine and transported via the lymphatic system to the liver, and is reduced by NADPH-CoQ reductase to become $\mathrm{H}_{2} \mathrm{CoQ}_{10}$, which has potent antioxidant action [20-22]. In human serum (plasma), $\mathrm{CoQ}_{10}$ is mostly present as $\mathrm{H}_{2} \mathrm{CoQ}_{10}$, and even if oxidized CoQ 10 is administered exogenously, the ratio of reduced $\mathrm{CoQ}_{10}$ to total $\mathrm{CoQ}_{10}$ remains the same [51]. Therefore, $\mathrm{H}_{2} \mathrm{CoQ}_{10}$, which is extremely unstable in air, is thought to exist in the body due to its role as an antioxidant.

In the present study, oral administration of statin decreased the resistance of heart and liver mitochondria to lipid peroxidation induced by $\mathrm{Fe}^{2+}$-ascorbate and transiently increased the production of TBARS (Tables 2 and 3). This increase in TBARS was alleviated by oral administration of $\mathrm{CoQ}_{10}$. Furthermore, oral administration of $\mathrm{CoQ}_{10}$ increased also NADPH-CoQ reductase activity, which was decreased by statin administration (Fig. 2). On the other hand, simvastatin also induced cessation of both spontaneous beating and stimulation-elicited beating in cultured cardiac myocytes (Fig. 1). This simvastatin-contractile impairment was prevented partially by pretreatment of cultured cardiac myocytes with $10 \mu \mathrm{M} \mathrm{CoQ}_{10}$. These results suggest that by coadministering $\mathrm{CoQ}_{10}$ and statin, sufficient amounts of $\mathrm{H}_{2} \mathrm{CoQ}_{10}$ are supplied to the body and maintained, thus alleviating the decreased oxidative stress resistance caused by statin administration.

\section{Necessity of $C o Q_{10}$ during oral administration of $H M G-C o A$ reductase inhibitor}

In 2001, the Ministry of Health, Labour and Welfare in Japan permitted the use of $\mathrm{CoQ}_{10}$ as a food additive as long as no claims were made about its pharmacological effectiveness and application. Now, many CoQ10-containing dietary and helath supplements are commercially available in Japan. While people mostly take $\mathrm{CoQ}_{10}$ for health maintenance or nutritional supplementation, as the size of the elderly population continues to increase in Japan, it is necessary to consider to the adverse reactions caused by drugs that are frequently prescribed to the elderly. The present study showed that statin administration decreased the body's resistance to oxidative stress, and one of the factors may be decreased CoQ levels. Therefore, we clarifies that when administering statin, it is desirable to elevate CoQ to normal levels, thus maintaining resistance to various oxidative stresses.

\section{Acknowledgments}

This work was supported in part by a Grant-in-Aid for Scientific Research (No. 16500429) from the Ministry of Education, Science and Culture, Japan, and Grand-in-Aid for Health Science Research as well as Grand-in-Aid for Cooperative Research (A) from Kobe Gakuin University, Japan. This research was also carried out in Coenzyme Q10 Biofunctional Research Center endowed by Shiseido Pharmaceutical Co. Ltd., Tokyo, Japan.

\section{References}

[1] Goldstein, J.L. and Brown, M.S.: Regulation of the mevalonate pathway. Nature, 343, 425-430, 1990.

[2] Maron, D.J., Fazio, S., and Linton, M.F.: Current perspectives on statins. Circulation, 101, 207-213, 2000.

[3] Bays, H.: Statin safety: an overview and assessment of the data-2005. Am. J. Cardiol., 97, 6C-26C, 2006.

[4] McKenney, J.M., Davidson, M.H., Jacobson, T.A., and Guyton, J.R.: National lipid association statin safety assessment task force.: Final conclusions and recommendations of the National Lipid Association Statin Safety Assessment Task Force. Am. J. Cardiol., 97, 89C-94C, 2006.

[5] Tobert, J.A., Bell, G.D., Birtwell, J., James, I., Kukovetz, W.R., Pryor, J.S., Buntinx, A., Holmes, J.B., Chao, Y.S., and Bolognese, J.A.: Cholesterol-lowering effect of mevinolin, an inhibitor of 3-hydroxy-3-methylglutaryl-coenzyme a reductase, in healthy volunteers. J. Clin. Invest., 69, 913919, 1982.

[6] Jacobson, T.A.: Statin safety: lessons from new drug applications for marketed statins. Am. J. Cardiol., 97, 44C-51C, 2006.

[7] Law, M. and Rudnicka, A.R.: Satin safety: a systematic review. Am. J. Cardiol., 97, 52C-60C, 2006.

[8] Jones, S.P., Teshima, Y., Akao, M., and Marban, E.: Simvastatin attenuates oxidant-induced mitochondrial dysfunction in cardiac myocytes. Circ. Res., 93, 697-699, 2003.

[9] De Pinieux, G., Chariot, P., Ammi-Said, M., Louarn, I., Lejonc, J.L., Astier, A., Jacotot, B., and Gherardi, R.: Lipidlowering drugs and mitochondrial function: effects of HMGCoA reductase inhibitors on serum ubiquinone and blood lactate/pyruvate ratio. Br. J. Clin. Pharmacol., 42, 333-337, 1996.

[10] Nakahara, K., Kuriyama, M., Sonoda, Y., Yoshidome, H., Nakagawa, H., Fujiyama, J., Higuchi, I., and Osame, M.: Myopathy induced by HMG-CoA reductase inhibitors in rabbits: a pathological, electrophysiological, and biochemical study. Toxicol. Appl. Pharmacol., 152, 99-106, 1998.

[11] Demyanets, S., Kaun, C., Pfaffenberger, S., Hohensinner, P.J., Rega, G., Pammer, J., Maurer, G., Huber, K., and Wojta, J.: Hydroxymethyl-glutaryl-coenzyme A reductase inbitors induce apoptosis in human cardiac myocytes in vitro. Biochem. Pharmacol., 71, 1324-1330, 2006.

[12] Rabkin, S.W. and Kong, J.Y.: Lovastatin-induced cardiac toxicity involves both oncotic and apoptotic cell death with 
the apoptotic component blunted by both caspase- 2 and caspase-3 inhibitors. Toxicol. Appl. Pharmacol., 193, 346355, 2003.

[13] Kaneta, S., Satoh, K., Kano, S., Kanda, M., and Ichihara, K.: All hydrophobic HMG-CoA reductase inhibitors induce apoptotic death in rat pulmonary vein endothelial cells. Atherosclerosis, 170, 237-243, 2003.

[14] Erl, W., Hristov, M., Neureuter, M., Yan, Z.Q., Hansso, G.K., and Weber, P.C.: HMG-CoA reductase inhibitors induce apoptosis in neointima-derived vascular sooth muscle cells. Atherosclerosis, 169, 251-258, 2003.

[15] Fouty, B.W. and Rodman, D.M.: Mevastatin can cause G1 arrest and induce apoptosis in pulmonary artery smooth muscle through a p27Kip1-independent pathway. Circ. Res., 92, 501-509, 2003.

[16] Sirvent, P., Mercier, J., Vassort, G., and Lacampagne, A.: Simvastatin triggers mitochondrial-induced $\mathrm{Ca}^{2+}$ signaling alteration in skeletal muscle. Biochem. Biophys. Res. Commun., 329, 1067-1075, 2005.

[17] Kalén, A., Norling, B., Appelkvist, E.L., and Dallner, G.: Ubiquinone biosynthesis by the microsomal fraction from rat liver. Biochim. Biophys. Acta, 926, 70-78, 1987.

[18] Takahashi, T., Okamoto, T., Mori, K., Sayo, H., and Kish, T.: Distribution of ubiquinone and ubiquinol homologues in rat tissues and subcellular fractions. Lipids, 28, 803-809, 1993.

[19] Kalén, A., Appelkvist, E.L., Chojnacki, T., and Dallner, G.: Nonaprenyl-4-hydroxybenzoate transferase. An enzyme involved in ubiquinone biosynthesis, in the endoplasmic reticulum-Golgi system of rat liver. J. Biol. Chem., 265, 1158-1164, 1990.

[20] Takahashi, T., Shitashige, M., Okamoto, T., Kishi, T., and Goshima, K.: A nevel ubiquinone reductase activity in rat cytosol. FEBS Lett., 314, 331-334, 1992.

[21] Takahashi, T., Yamaguchi, T., Shitashige, M., Okamoto, T., and Kishi, T.: Reduction of ubiquinone in membrane lipids by rat liver cytosol and its involvement in the cellular defense system against lipid peroxidation. Biochem. J., 309, 883890, 1995.

[22] Kishi, T., Takahashi, T., Mizobuchi, S., Mori, K., and Okamoto, T.: Effect of dicumarol, a NAD(P)H: quinone acceptor oxidoreductase 1 (DT-diaphorase) inhibitor on ubiquinone redox cycling in cultured rat hepatocytes. Free Radic. Res., 36, 413-419, 2002.

[23] Beyer, R.E., Segura-Aguilar, J., Di Bernardo, S., Cavazzoni, M., Fato, R., Fiorentini, D., Galli, M.C., Setti, M., Landi, L., and Lenaz, G.: The role of DT-diaphorase in the maintenance of the reduced antioxidant form of coenzyme Q in membrane systems. Proc. Natl. Acad. Sci. USA., 93, 2528-2532, 1996.

[24] Landi, L., Fiorentini, D., Galli, M.C., Segura-Aguilar, J., and Beyer, R.E.: DT-diaphorase maintains the reduced state of ubiquinones in lipid vesicles thereby promoting their antioxidant function. Free Radic. Biol. Med., 22, 329-335, 1997.

[25] Xia, L., Nordan, T., Olsson, J.M., Damdimopoulos, A., Bjorkhem-Bergman, L., Nalvarte, I., Eriksson, L.C., Arner, E.S., Spyrou, G., and Bjornstedt, M.: The mammalian cytosolic selenoenzyme thioredoxin reductase reduces ubiquinone. A novel mechanism for defense against oxidative stress. J. Biol.
Chem., 278, 2141-2146, 2003.

[26] Olsson, J.M., Xia, L., Eriksson, L.C., and Bjornstedt, M.: Ubiquinone is reduced by lipoamide dehydrogenase and this reaction is potently stimulated by zinc. FEBS Lett., 448, 190192, 1999.

[27] Xia, L., Bjornstedt, M., Nordman, T., Eriksson, L.C., and Olsson, J.M.: Reduction of ubiquinone by lipoamide dehydrogenase. An antioxidant regenerating pathway. Eur. J. Biochem., 268, 1486-1490, 2001.

[28] Frei, B., Kim, M.C., and Ames, B.N.: Ubiquinol-10 is an effective lipid-soluble antioxidant at physiological concentrations. Proc. Natl. Acad. Sci. USA., 87, 4879-4883, 1990.

[29] Stocker, R., Bowry, V.W., and Frei, B.: Ubiquinol-10 protects human low density lipoprotein more efficiently against lipid peroxidation than does alpha-tocopherol. Proc. Natl. Acad. Sci. USA., 88, 1646-1650, 1991.

[30] Kagan, V.E., Serbinova, E.A., Koynova, G.M., Kitanova, S.A., Tyurin, V.A., Stoytchev, T.S., Quinn, P.J., and Packer, L.: Antioxidant action of ubiquinol homologues with different isoprenoid chain length in biomembranes. Free Radic. Biol. Med., 9, 117-126, 1990.

[31] Yamamoto, Y., Komuro, E., and Niki, E.: Antioxidant activity of ubiquinol in solution and phosphatidylcholine liposome. $J$. Nutr. Sci. Vitaminol., 36, 505-511, 1990.

[32] Landi, L., Cabrini, L., Fiorentini, D., Stefanelli, C., and Pedulli, G.F.: The antioxidant activity of ubiquinol-3 in homogeneous solution and in liposomes. Chem. Phys. Lipids., 61, 121-130, 1992.

[33] Kamei, M., Fujita, T., Kanbe, T., Sasaki, K., Oshiba K., Otani, S., Matsui-Yuasa, I., and Morisawa, S.: The distribution and content of ubiquinone in foods. Int. J. Vitam. Nutr. Res., 56, 57-63, 1986.

[34] Szkopinska, A.: Ubiquinone. Biosynthesis of quinine ring and its isoprenoid side chain. Intracellular localization. Acta Biochim. Pol., 47, 469-480, 2000.

[35] Crane, F.L.: Biochemical functions of coenzyme Q10. J. Am. Coll. Nutr., 20, 591-598, 2001.

[36] Willis, R.A., Folkers, K., Tucker, J.L., Ye, C.Q., Xia, L.J., and Tamagawa, H.: Lovastatin decreases coenzyme Q levels in rats. Proc. Natl. Acad. Sci. USA, 87, 8928-8930, 1990.

[37] Ghirlanda, G., Oradei, A., Manto, A., Lippa, S., Uccioli, L., Caputo, S., Greco, A.V., and Littarru, G.P.: Evidence of plasma CoQ10-lowering effect by HMG-CoA reductase inhibitors: a double-blind, placebo-controlled study. J. Clin. Pharmacol., 33, 226-229, 1993.

[38] Passi, S., Stancato, A., Aleo, E., Dmitrieva, A., and Littarru, G.P.: Statins lower plasma and lymphocyte ubiquinol/ ubiquinone without affecting other antioxidants and PUFA. Biofactors, 18, 113-124, 2003.

[39] Folkers, K., Langsjoen, P., Willis, R., Richardson, P., Xia, L.J., Ye, C.Q., and Tamagawa, H.: Lovastatin decreases coenzyme Q levels in humans. Proc. Natl. Acad. Sci. USA, 87, 8931-8934, 1990.

[40] Sirvent, P., Bordenave, S., Vermaelen, M., Roels, B., Vassort, G., Mercier, J., Raynaud, E., and Lacampagne, A.: Simvastatin induces impairment in skeletal muscle while heart is protected. Biochem. Biophys. Res. Commun., 338, 1426-1434, 2005. 
[41] Goshima, K.: Ouabain-induced arrhythmias of single isolated cardiac myocytes and cell clusters cultured in vitro and their improvement by quinidine. J. Mol. Cell, Cardiol., 9, 7-23, 1977.

[42] Nakamura, T.Y., Goda, K., Okamoto, T., Kishi, T., Nakamura, T., and Goshima, K.: Contractile and morphological impairment of cultured fetal mouse myocytes induced by oxygen radicals and oxidants. Correlation with intracellular $\mathrm{Ca}^{2+}$ concentration. Circ. Res., 73, 758-770, 1993.

[43] Allain, C.C., Poon, L.S., Chan, C.S., Richmond, W., and Fu, P.C.: Enzymatic determination of total serum cholesterol. Clin. Chem., 20, 470-475, 1974.

[44] Okamoto, T., Fukunaga, Y., Ida, Y., and Kishi, T.: Determination of reduced and total ubiquinones in biological materials by liquid chromatography with electrochemical detection. J. Chromatogr., 430, 11-19, 1988.

[45] Takei, M., Hiramatsu, M., and Mori, A.: Inhibitory effects of calcium antagonists on mitochondrial swelling induced by liquid peroxidation or arachidonic acid in the rat brain in vitro. Nurochem. Res., 19, 1199-1206, 1994.

[46] Takahashi, T., Okamoto, T., and Kishi, T.: Characterization of NADPH-dependent ubiquinone reductase activity in rat liver cytosol: effect of various factors on ubiquinone-reducing activity and discrimination from other quinone reductase. $J$. Biochem., 119, 256-263, 1996.

[47] Lowry, O.H., Rosebrough, N.J., Farr, A.L., and Randall, R.J.: Protein measurement with the Folin phenol reagent. J. Biol. Chem., 193, 265-275, 1951.

[48] Takahashi, T., Sugimoto, N., Takahata, K., Okamoto, T., and Kishi, T.: Cellular antioxidant defense by a ubiquinolregenerating system coupled with cytosolic NADPHdependent ubiquinone reductase: Protective effect against carbon tetrachloride-induced hepatotoxicity in the rat. Biol. Pharm. Bull., 19, 1005-1012, 1996.

[49] Okamoto, T., Fukui, K., Nakamoto, M., Kishi, T., Kanamori, R., Kataoka, K., Nishii, S., Kishi, H., Hiraoka, E., and Okada, A.: Serum levels of coenzyme $\mathrm{Q}_{10}$ and lipids in patients during tatal parenteral nutrition. J. Nutr. Sci. Vitaminol., 32, $1-12,1986$.

[50] Kalén, A., Appelkvist, E.L., and Dallner, G.: Age-related changes in the lipid composition of rat and human tissues. Lipids, 24, 579-584, 1989.

[51] Okamoto, T., Matsuya, T., Fukunaga, Y., Kishi, T., and Yamagami, T.: Human serum ubiquinol-10 levels and relationship to serum lipids. Int. J. Vitam. Nutr. Res., 59, 288292, 1989. 